Pietro M. Liuzzo

\title{
17 EAGLE Continued: IDEA. The International Digital Epigraphy Association
}

\begin{abstract}
Few disciplines can boast of having digitized almost the entirety of the documents they are interested in, and to have so many scholars active in digitization projects, as in Greek and Latin epigraphy (Orlandi et al., 2014; Orlandi et al., 2017). This paper will present some of the methodological issues faced by the Europeana network for Ancient Greek and Latin Epigraphy, before and after the end of the project when its activities were moved to the International Digital Epigraphy Association. It will give some examples to demonstrate how the above-mentioned achievement is far from being enough to support real user cases. Particularly, problems of mapping will be presented with an evaluation of the current quality of the data, and some hints to the continuing work of the IDEA association for the EAGLE portal and associated resources.
\end{abstract}

Keywords: Greek epigraphy, Latin epigraphy, up-conversion, collaboration, Epigraphy.info

\subsection{The EAGLE Project Steps}

\subsubsection{The EAGLE Aggregator}

Within the EAGLE project (Europeana Network for Ancient Greek and Latin Epigraphy) a model was established, based on the principles of the TEI/EpiDoc standard (Amato et al., 2013; Manghi et al., 2015) that was able to guarantee easy mapping to the CIDOC$\mathrm{CRM}^{1}$ and to EDM (Europeana Data Model) for harvesting purposes. ${ }^{2}$ As a result, this work has made possible not only the development of the EAGLE portal, with its search functionalities across data from several different sources, but has also allowed the

1 [http://www.cidoc-crm.org/].

2 [https://pro.europeana.eu/resources/standardization-tools/edm-documentation].

Pietro M. Liuzzo, Universität Hamburg 
creation of a large network of partners, and produced additional resources such as the EAGLE Vocabularies and the Virtual Exhibition. ${ }^{3}$

\subsubsection{The EAGLE Portal}

The EAGLE portal is an entry point to the content of the collections participating in the project, not only the databases of the original EAGLE - Electronic Archive of Greek and Latin Epigraphy (Epigraphic Database Heidelberg, Epigraphic Database Rome, Epigraphic Database Bari and Hispania Epigraphica Online), ${ }^{4}$ but also many other projects like Ubi erat lupa, Last Statues of Antiquity, the Ancient Graffiti Project and, at the end, part of the Epigraphic Database Clauss Slaby. ${ }^{5}$ It can be confidently stated that almost all of the existing digital epigraphic projects were in some way linked with the EAGLE project during and after its lifetime. Here are some features of the EAGLE portal in brief:

1. it has a data aggregator that mainly harvests EpiDoc XML exports of a rich, but minimal, set of information from the contributing partners. It also makes them searchable in one place for end users, as well as harvestable for Europeana, the European portal of cultural heritage. ${ }^{6}$ Anyone can make its contents part of EAGLE. Anyone can reuse this data, ${ }^{7}$

2. it groups and organizes results based on a unique ID given by Trismegistos (TM), thus offering parallel results for one text,

3. thanks to an image based search system, it makes the collections searchable, for the first time, also by images,

4. it has harmonized vocabularies in use for several descriptive fields, ${ }^{8}$

5. it has developed - and is linked to - a set of services, like a big collection of translations of inscriptions (Bigi, 2014), ${ }^{9}$ a storytelling application ${ }^{10}$ and a Virtual Exhibition, "Signs of Life" which collects images, 3D models, infographics and many other types of materials to give an introduction to non-experts (Liuzzo, Mambrini, \& Franck, 2017).

3 An early version of this paper was presented with Silvia Orlandi at the international congress of Latin and Greek epigraphy in Wien, 2017/8/29.

4 [http://www.eagle-eagle.it/Italiano/index_it.htm].

5 [https://www.eagle-network.eu/eagle-project/partners/].

6 [https://www.europeana.eu].

7 Although this is never as easy as one would like, and requires some work from the system maintainers. The IDEA association carries out this work as part of its mission for member institutions. See below for an example.

8 [https://www.eagle-network.eu/resources/vocabularies/].

9 The Eagle Media Wiki for Translations of inscriptions [https://wiki.eagle-network.eu/wiki/Main_Page].

10 [https://www.eagle-network.eu/resources/flagship-storytelling-app/]. 
Both the portal and the services created by EAGLE are still working after the official end of the European project in March 2016. However, they need to be maintained, constantly updated and possibly improved, as the EAGLE experience has also highlighted the limits and the problems of digital resources.

\subsection{IDEA}

After the end of the EAGLE project, IDEA, the International Digital Epigraphy Association, was founded, with the aim of maintaining the EAGLE resources and continuing on the path of cooperation and integration of resources. It also aimed to cross the boundaries of single projects and move towards the creation of a Epigraphy.info resource (Feraudi-Gruénais \& Grieshaber, 2016), based on the model already used by papyrologists. ${ }^{11}$ IDEA has, as its primary aim, to continue the networking efforts of the EAGLE project and to maintain its outputs, with a very practical approach: keep the EAGLE portal infrastructure running, together with its functionalities, supporting members who want to contribute, advising new projects on what is and isn't available, keeping an eye on the developments in the field and sharing this knowledge to increase the possibility of more effective and organized work on digital epigraphy.

IDEA currently supports its members and prospective members in a range of activities, from data curation and consultancy on how to set up new digital epigraphic projects, to the upload of new data from existing content providers who continue to update their resources locally.

Actual activity for the current year included, for example:

- aggregation of data from existing partners still actively updating their resources (occasional and not systematic or planned, due to lack of resources),

- continued collaboration with network members and with active projects (e.g. Pondera project, ${ }^{12}$ IGCyr and GVCyr, ${ }^{13}$ Iscrizioni Latine Arcaiche ${ }^{14}$ ),

- server migration and maintenance,

- $\quad$ updates to the EAGLE vocabularies. ${ }^{15}$

11 The Papyrological Navigator and Editor [http://papyri.info/]. This model has been superseded by a more distributed data exchange model since the Epigraphy.info meeting held in Heidelberg 21-23 March 2018.

12 [https://pondera.incal.ucl.ac.be/].

13 [https://igcyr.unibo.it/].

14 This project is not yet online.

15 [https://www.eagle-network.eu/resources/vocabularies/]. 


\subsection{Methodological Issues Faced During EAGLE}

Mapping and harmonizing the data (as far as possible) from the databases to a minimum set of standardized information, was the primary aim of one of the working groups in EAGLE (Liuzzo, 2017). EpiDoc was the obvious choice, but because of the scope and obligations of the project there was no conversion of the existing databases to an XML workflow. Rather, an additional workflow was generated to export this format for the purposes of aggregation and to allow a common portal to search across databases.

This process meant that each participating database or project had to contribute an export of its data, produced with its resources or those common to the project, validating to the EAGLE schema. This was a stricter version of the EpiDoc schema from which it was generated, with a minimal set of information required by the common definition.

The efforts here went into making this limited information, packed into a strict schema originally intended for database and aggregation purposes, as rich as possible. This would allow further reuse, demonstrating its usefulness as a large corpus of disambiguated information.

We focused on the alignment and harmonization of the vocabularies used for the descriptions of inscriptions and on the up-conversion of the string text into XML (Liuzzo, Fasolini, \& Rocco, 2014).

The first task began with the acquisition of all lists used by the partners. We attributed IDs to each concept and then aligned the terms used, marking the language in which they appeared. We immediately faced decisions, such as that of the "main language". The vocabularies still claim to be in English, although it was expressly declared that the choice of the language for the main label for each concept would not be in one of the many languages represented in the network, but rather prioritize those terms that also had an associated definition. Thus, in the tabular view of the full vocabulary one can see terms in Latin, English and German as the main label (Figure 17.1).

Programmatically speaking, this is something of a problem. However, it better reflects the reality, where a translation of a concept from Italian to English does not correspond to how an English-speaking project labels that concept. There are many reasons for this, such as, the different definition in the context taken into consideration of a certain text typology, or the major or minor degree of precision in the labelling of types. The EAGLE vocabularies want to be inclusive, rather than selective, and help the alignment and connection of entities rather than forcing a denomination or a language to any description. These vocabularies continued to raise interest and continued to receive contributions after the end of the project, especially from the Ancient Graffiti project ${ }^{16}$ and the I.Sicily project ${ }^{17}$.

16 [http://ancientgraffiti.wlu.edu/] (Benefiel, Sypniewski, \& Sprenkle, 2017).

17 [http://sicily.classics.ox.ac.uk/] (Prag, 2017). See Chapter 19 in this volume. 


\begin{tabular}{|c|c|c|c|}
\hline \multicolumn{3}{|l|}{ Adnuntiatio } & la \\
\hline & Translated term & munera & la \\
\hline & Definition & $\begin{array}{l}\text { Bekanntmachung; } \\
\text { Ankündigung (z. } \\
\text { B. von munera) } \\
\text { Nicht Rechtliche } \\
\text { Verfügungen } \\
\text { (s.Rechtliche } \\
\text { Verfügung, } \\
\text { öffentlich / privat) }\end{array}$ & de \\
\hline & Examples & HD053407 & de \\
\hline & Created & $\begin{array}{l}2013-08-01 \\
12: 27: 53\end{array}$ & \\
\hline & Modified & $\begin{array}{l}2013-08-15 \\
16: 56: 04\end{array}$ & \\
\hline \multirow{4}{*}{$\begin{array}{l}\text { agonistic / } \\
\text { ludic }\end{array}$} & & & en \\
\hline & Translated term & agonistic / ludic & en \\
\hline & Translated term & agonistic / ludic & en \\
\hline & Created & $\begin{array}{l}2014-03-13 \\
11: 28: 02\end{array}$ & \\
\hline \multirow[t]{3}{*}{ Akklamation } & & & de \\
\hline & Translated term & Acclamation & $\mathrm{fr}$ \\
\hline & Translated term & Aclamación & es \\
\hline
\end{tabular}

Figure 17.1: Main terms in different languages in the Type of Inscription EAGLE Vocabulary

The EpiDoc guidelines are, to date, a de facto standard for any new epigraphic project, digital or not, and have gone well beyond the limits of classical epigraphy, being used for a range of projects outside of the Mediterranean milieu (Elliott et al., 2007-2013). ${ }^{18}$ The most interesting and rewarding feature of the encoding schema suggested is the encoding of the text, and this is the area where more effort has been focused. We had texts similar to the following (EDR000085) that needed to be converted to the EpiDoc XML with an automated process and then displayed on the portal with a unified edition style: ${ }^{19}$

$$
\begin{gathered}
\text { [---? deposit]us in paç[e ---?], } \\
\text { [cons(ulatu) Nicomaci Fl]ạbiani } \bar{v}(\text { iri) [c(larissimi)]. }
\end{gathered}
$$

18 An idea of the number of projects is given by this category page on the Digital Classicist wiki [http://wiki.digitalclassicist.org/Category:EpiDoc]. See also Chapters 1 and 6 in this volume. 19 [http://www.edr-edr.it/edr_programmi/res_complex_comune.php?id_nr=EDR000085]. 
The rudimental up-conversion ${ }^{20}$ stylesheets used returned this result:

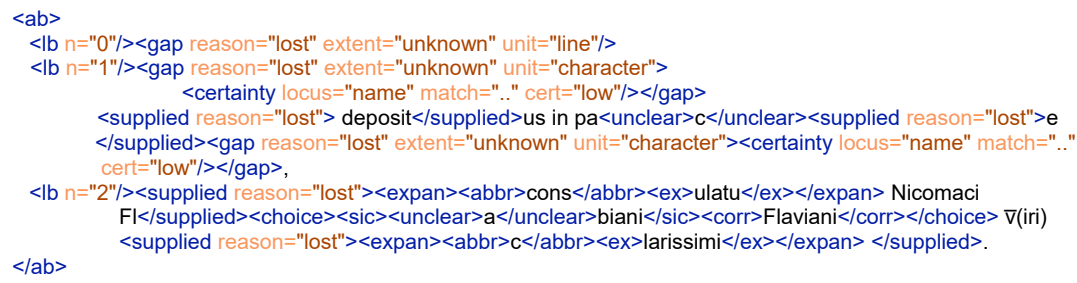

This is then visible on the portal as follows:

$$
\begin{gathered}
{[---] /[-- \text { ? deposit]us in paç [e ---?], / [cons(ulatu) Nicomaci }} \\
\text { Fl] } \text { Flaviani }^{7} \bar{v}(\text { iri })[\text { [C(larissimi) }] .
\end{gathered}
$$

You will immediately notice where the problems are:

1. the abbreviation $\bar{v}$ (iri) is not matched,

2. the corrected version of the word flaviani instead of flabiani, as on the stone, is wrongly encoded; the <supplied > element should have been split to have Fl inside the element $<$ sic $>$ of the $<$ choice $>$ and then unified in the visualization with the previous $<$ supplied $>$ element,

3. an unwanted space appears in the last portion of text supplied by the editor after the expansion of the abbreviation for clarissimi.

The user would have noticed almost nothing on the portal if we had decided to show the content of the element $<$ sic $>$ instead of $<$ corr $>$. He/she still does not see the error for the first problem, $\bar{v}$ (iri), which remains untouched, as in the source, by the XSLT rendering the text.

This is clarified in the portal to guide the users, but it remains a problem to be resolved by improving the algorithms for the up-conversion, or fixing by hand where needed.

However, too many hands would be needed for more than 500,000 inscriptions. Therefore, the first solution and especially the second need to be implemented collaboratively (Feraudi-Gruénais \& Grieshaber, 2016).

It was not only data from various types of databases that had to be exported and mapped. EpiDoc data needed to be converted to the EAGLE EpiDoc. Needless to say, it took orders of magnitude less time and effort to do this, and in these cases no text up-conversion was needed and the correctness of the mark-up was guaranteed by the content provider.

20 The proceeding of the latest Balisage Markup Conference are very instructive on this topic (Proceedings of Balisage: The Markup Conference 2017, 2017). 
Still, there are other problems related to the time available for the transformation, which lead to inconsistency in the data display. One could test this, which is fortunately "only" a visualization problem for correct underlying data, searching for one of the Roman Inscriptions of Britain, which often have three parallel editions in the EAGLE data.

Let us look for example at TM 154498, which is present in RIB, EDCS and EDH. The RIB $5^{21}$ XML for the text looks like this:

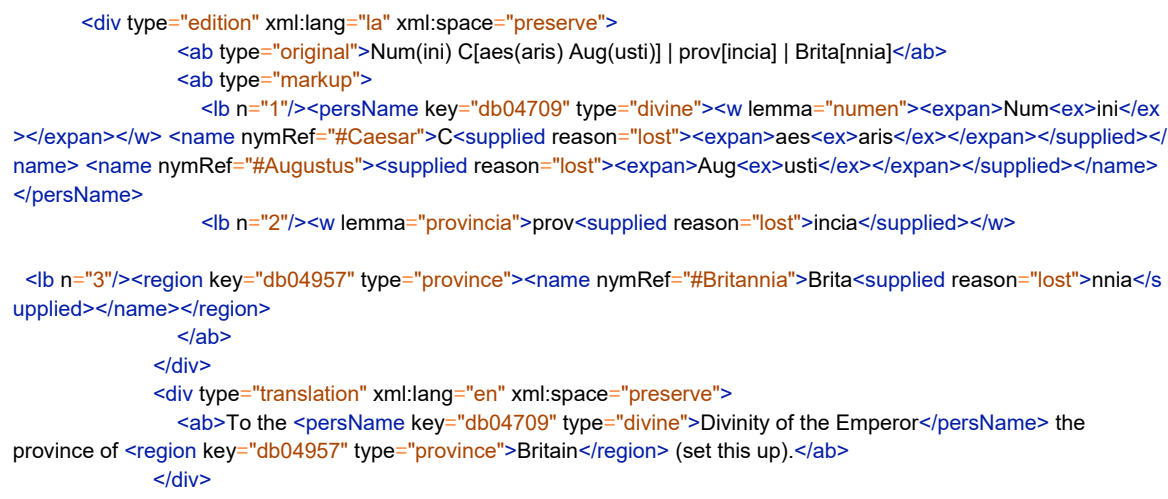

EDCS-07800230 22 after transformation and up-conversion has the following XML, which is equal to that independently produced exporting HD069342 23 :

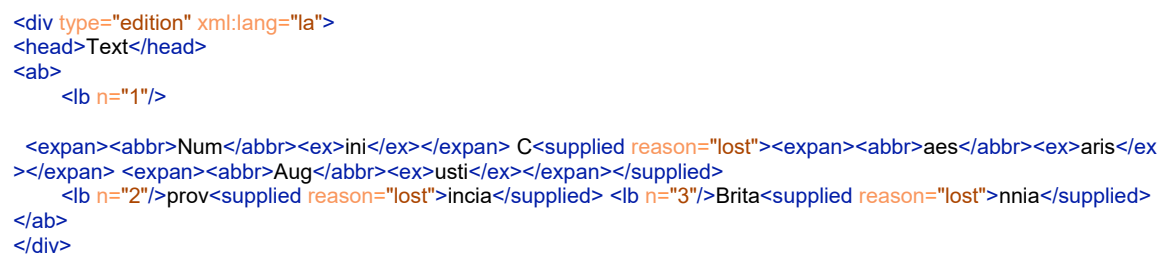

The visualization of RIB on the portal to date apparently takes both the $<a b>$ inside $<$ div type $=$ "edition" $>$ as well as the translation.

Given the volume of data and issues that we encountered during the project, several minor issues still remain to be resolved. This will happen in the very near future, once a particular member of the association, with knowledge and access to the data, is available to solve them. If the application and the data were collectively maintained, this would not need to wait so long.

Specificities in encoding are fine, and EpiDoc does a great job of allowing enough rigour and enough flexibility, thus serving perfectly its aim and its diverse users. Still

21 [https://romaninscriptionsofbritain.org/inscriptions/5].

22 [http://db.edcs.eu/epigr/edcs_id.php?s_sprache=en\&p_edcs_id=EDCS-07800230].

23 [http://edh-www.adw.uni-heidelberg.de/edh/inschrift/HD069342]. 
we must be aware it is not enough alone and does not do magic just because is EpiDoc. We need to do more and better EpiDoc, and to keep training people and making it a research quality point for new students and scholars.

\subsection{Methodological Issues Faced After EAGLE}

We tried never to say that the mappings and conversions were perfect. ${ }^{24}$ They are not, and still they serve a great function and lead the way for much more. Let us list some methodologically critical points in the harmonization process once more:

- some partners did not provide EpiDoc at all and preferred to deliver the data with other formats (their data has never been up-converted),

- some partners sent their data too late and the up-conversion could not be made precise enough,

- some partners do not strictly follow data entry guidelines and the up-conversion process fails more often than it should, relying on consistency, ${ }^{25}$

- the export and transformation workflow will always need checking and updating, thus it is not sustainable as a workflow, ${ }^{26}$

- some datasets have TM IDs and some not,

- some datasets add to some elements references to Trismegistos GEO IDs, some others do not,

- the editing of the vocabularies follows a GitHub based workflow which is efficient but not particularly user friendly. ${ }^{27}$

Let us take as an example a task that sounds easy. ${ }^{28}$ Let us try to extract EAGLE data about the provinces relevant for a specific project like LatinNow. ${ }^{29}$ Besides temporary issues of the portal, where sometimes the actual XML cannot be downloaded and the function to export results only saves the one in the current view, the results obtained with any general search would have been partial. This is the case with any database, as the user is constrained by the provided functionality. But in this case I could easily,

24 On data flow quality (Mannocci, 2017).

25 A test analysis of the cleanliness of data was done in 2014 for EDH, with astonishingly good results and a very high level of cleanness in the data entered.

26 The CNR-ISTI built a very useful Content Checker, unfortunately very little used by the partners, which should be valorised in the future.

27 An accessible editor integrated in the workflow is missing although many exist and one was developed within EAGLE as well by the CNR-ISTI team.

28 All data analysis has been carried out using XQuery in a local version of exist-db 3.5 [http://existdb.org].

29 ERC project LatinNow (Latinization of the north-western Roman provinces: sociolinguistics, epigraphy and archaeology, grant number 715626) [https://latinnow.eu/], PI Alex Mullen. 
thanks to the IDEA association, access all the EAGLE data to provide a better answer and deliver the required data. ${ }^{30}$

The data from the content providers uses different definitions of provinces, depending, for example, on the time scope of the original database or on internal definitions.

We must first isolate the data belonging to the selected provinces. In the EAGLE EpiDoc model this is information stored in a TEI element <placeName type $=$ "provinceItalicRegion" $>$ which, in the expectations of users, should be indexed by the aggregator to provide a filter "by province" and provide the functionality to search with this criterion, even if different denominations have been used, i.e. avoiding the bare string matching. The assumption is that the field is aligned to a Trismegistos GEO ID and that this is used as a key to group different denominations (Evangelisti, Liuzzo, \& Verreth, 2014; Verreth, 2017). For example, by the documentation I would expect an inscription from Lusitania to have the following tag:

$<$ placeName
ref="http://www.trismegistos.org/place/5531"
type="provinceItalicRegion"
Lusitania
$</$ placeName $>$

However, working directly with the current raw data in EAGLE, the values of this element are quite different. Out of 412,757 document entities in the dataset with this $<$ placeName $>$ tag (i.e. almost 100k do not have any), only 77,303 have a @ref pointing to the Trismegistos GEO ID. ${ }^{31}$ There is also some expected 'dirtiness', like some data with <placeName type="provincItalicRegion" $>$ instead of the correct value of the attribute @type. For this reason, no filter by province is offered. The results would be more imprecise than searching for Lusitania, in the place of provenance. Actually, querying the data directly, there are 277 different values for this element and for example, "Narbonensis" appears in Gallia Narbonensis, Narbonensis, Narbonensis?, Narbonensis II, Narbonensis I. This is an acceptable workaround for the website, as it is intuitive without forcing high expectations. The user knows that the portal is an aggregator of heterogeneous data and will most often use this parameter, together with others, to run not one search but several. Since the volume of aligned entities

30 The observations made here are based on data downloaded 2017/10/31. Many thanks go especially to Claudio Atzori, Andrea Mannocci and Franco Zoppi at CNR-ISTI in Pisa who have answered my requests faster than one could ever expect.

31 Many more have this for the precise find-spot instead, which allows us to offer in the website the ancient find-spot filter with a decent degree of reliability. Of these 77,303 almost all are records from the Epigraphic Database Heidelberg. 
is not sensible compared to the corpus, one must take into account the diversity of values and group-values that probably belong to the same province of interest by hand.

Once we have all document entities referring to one of the values for the province (thus reasonably all the entities referring to the desired province), these need to be grouped by TM ID to have unique texts and their multiple editions. This is possible only to the extent to which there is such information in the data, and that it is updated and correct; this is not easy. In the dataset used for this paper, 391,227 documental entities of a total of 502,961 have at least one. The EAGLE aggregator can attribute many more on the basis of the updated Trismegistos IDs, even without injecting this information in the source data. Some content providers actually could not, during the life of the project, enter these IDs that became available later.

Trismegistos has accomplished the incredible task of disambiguating all existing digitized texts during the lifetime of the EAGLE project. However, the process of updating this information in the databases had to follow a procedure where the valuable correspondence tables were sent over from one partner to another. Within the scope of its action, IDEA has developed a small tool, based at the University of Hamburg, which serves this data via a data API. This tool can respond dynamically to the request for parallel texts connected to a Trismegistos ID, either starting the query from a local id, or from a Trismegistos ID and returning several common formats for developers to easily reuse the information in their applications. ${ }^{32}$

\subsection{General Issues in Digital Epigraphy}

There are currently several general issues in the field of epigraphic databases. I will list some and omit more general issues, e.g. the use of closed or private and inaccessible databases to provide results in publications and presentations, thus cutting out the verifiability of the results presented. This is a poor practice that we have observed in plenary presentations at international conferences. The following are just five selected points:

1. researchers who are not IT specialists, such as historians and philologists, are forced to traipse across an assortment of databases when seeking information about inscriptions, EAGLE being one of them in some cases, especially thinking of the lack of Greek texts;

2. the wealth of information inscribed within texts, the connections between text, support and context have been discussed extensively but are still largely

32 Since this article has been submitted a major improvement has taken place, as this service in a much better and richer way is provided directly by Trismegistos texrelations API at [https://www. trismegistos.org/dataservices/texrelations/documentation/]. 
underexploited in print, where little can be done about it, but also in digital resources where these connections when explicit could be easily and fruitfully used; ${ }^{33}$

3. resources in attested languages of which the researcher is not aware become blind spots, which is in contradiction with the multilingual nature of societies of the past;

4. crucially, these resources fail to be adequately referenced and used across publications in the epigraphic realm;

5. only authors and editorial teams can directly contribute, all others have to take more or less complicated workarounds.

Some other, more specific issues could be listed for projects like EAGLE, where the aim of aggregating data for Europeana has forced some definitions at different levels (Liuzzo, 2015). However issues are not what should stop us, but rather should help us to progress. The interaction of different resources, a virtue of any discipline that no project should propose to obliterate, is a huge challenge, and problems in the processes such as those encountered are not surprising.

The first issue could be easily overcome through an aggregator such as EAGLE, if aggregation did not imply regular updates. These are not always possible, especially if a contributing project is discontinued or does not have the human resources to implement it.

The second issue has been only partially faced by EAGLE. The EAGLE vocabularies and the partial EpiDoc encoding of the text go in this direction, allowing the visualization of related results based on one of the aligned features, but the automated mark-up needs to be edited and can only be considered a facilitator for the beginning of a real digital edition, rather than the final product of a process. Existing projects requesting EAGLE data for other purposes are the ideal user of this data and have been numerous. The EPNet project ${ }^{34}$ is using the very promising federated databases approach (Calvanese et al., 2016) and the CRMtex group is also making a very positive effort for the creation of a CIDOC-CRM model for epigraphy (Felicetti \& Murano, 2016; Ruiz, Vassallo, \& Liuzzo, 2014).

The third issue is more interesting because it is an issue of the discipline, not only of digital resources, which can be really supported by new digital resources thus serving not just the immediate needs of current research, but opening up an entirely new set of questions and possibilities for it. Beside the examples of the CIIP (Cotton et al., 2010) and I.Sicily a comprehensive Epigraphy, without further labels,

33 Only EAGLE has, to my knowledge a rudimental attempt to show significantly related resources. The IDEs project [https://blogs.library.duke.edu/dcthree/projects/] is instead doing this in a much cleverer way for Greek inscriptions.

34 [http://www.roman-ep.net/wb/2016/12/22/ceipac-database-updated/]. 
has never existed, not to speak of any comparative effort, and could in fact not exist until this days when it can be leveraged by proper tools..$^{35}$ Digital tools based on properly curated and linked data can help the researcher on these points.

The fourth problem is again one outside the strict realm of digital epigraphy, but affects all digital resources. Why should a contribution to an online resource which everyone uses and reads not be evaluated and accounted for in the evaluation of the scientific activity of a researcher as a paper, when this is also properly peer reviewed? There is here a hole in the more general system, but also digital resources have not done their part to make it possible and easy, although it could have been easier than thought. Now there is really no more excuse for researchers not to properly cite digital resources, as there is no excuse for digital resources not being easily and readily citable. Nevertheless, it is very rare to find the precise citation of digital resources in papers, as it is difficult to find the proper method to cite a digital resource. To make the citation of epigraphic digital resources possible, will be one of the central scopes of the already mentioned editor \& navigator Epigraphy. info (Feraudi-Gruénais \& Grieshaber, 2016). ${ }^{36}$ The point of the evaluation of such research products needs to be discussed in the proper venues and certainly requires far-sighted advocates.

The last issue highlighted here, is dependent on the previous one and requires the biggest leap of faith: opening one's own editorial work to the contributions of others. Assuming we start thinking of digital editions as critical editions, we edit them as such and we offer them to the public as such, then we need a further step to make them editable by others.

The work carried out to facilitate digital publication has also received, in the last year, a major input with the release of EFES (EpiDoc Front-End Services), ${ }^{37}$ EVT 2 beta 1 (Edition Visualization Technology) ${ }^{38}$ and TEI-Publisher for exist-db. ${ }^{39}$ This last, which I have personally tested, allows direct publication of TEI files in a way that has never been so easy (Turska, Cummings, \& Rahtz, 2016; Wicentowski \& Meier, 2015). It is usable out-of-the-box for TEI Simple, but it is also very easy to use with the EpiDoc ODD.

35 Only Trismegistos to my knowledge does host and integrate data in all different languages.

36 [http://epigraphy.info/].

37 [https://github.com/EpiDoc/EFES].

38 [http://evt.labcd.unipi.it/].

39 [http://teipublisher.com/index.html]. 


\subsection{Conclusions}

Whilst it has never been possible to directly enrich a specific dataset with data from other datasets, no comparative approach has ever been served by a digital resource for inscriptions either. These would greatly enhance the range of possible research questions that could be addressed. Research has always remained within linguistic, chronological and spatial boundaries that EAGLE, for the first time, attempted to overcome, hosting inscriptions in all languages. In addition, it is to be noted that epigraphic research lacks entirely, not just digitally, a viable way to view the current status of digitization. Instead, some online resources are happy with giving the false impression that "everything" is already there, thus building a chain of misunderstandings, leading to the misuse of online resources. Few disciplines can be as proud of having so many texts online as classical epigraphy. For even fewer, it would make more sense to have a common overview of who is doing what and where and to ensure that the increasingly limited resources are not wasted in the repetition of tasks, whilst other research areas remain forever untouched.

\section{Bibliography}

Amato, G., Bollettieri, P., Gennaro, C., Manghi, P., Mannocci, A., \& Zoppi F. (2013). AIM Infrastructure Specification. [Report of the project EAGLE]. Retrieved from [https://www. eagle-network.eu/wp-content/uploads/2013/06/EAGLE_D4.1_AIM_Infrastructure_ Specification_update.pdf], 2017/10/31.

Benefiel, R., Sypniewski, H., \& Sprenkle, S. (2017). Working with Text and Images: The Graffiti of Herculaneum. In S. Orlandi, R. Santucci, F. Mambrini, \& P.M. Liuzzo, (Eds.), Digital and Traditional Epigraphy in Context. Proceedings of the EAGLE 2016 International Conference (pp. 145-159). Roma: Sapienza Università Editrice. doi: 10.13133/978-88-9377-021-7

Bigi, F. (2014). Towards an EAGLE Standard in Translating Inscriptions. In S. Orlandi, R. Santucci, V. Casarosa, \& P.M. Liuzzo (Eds.), Information Technologies for Epigraphy and Cultural Heritage: Proceedings of the First EAGLE International Conference (Serie antichistica. Collana Convegni 26) (pp. 167-178). Roma: Sapienza Università Editrice. Retrieved from [https://www.eaglenetwork.eu/wp-content/uploads/2015/01/Paris-Conference-Proceedings.pdf], 2017/11/30.

Calvanese, D., Liuzzo, P., Mosca, A., Remesal, J., Rezk, M., \& Rull, G. (2016). Ontologybased data integration in EPNet: Production and distribution of food during the Roman Empire. Engineering Applications of Artificial Intelligence, 51, 212-229. doi: 10.1016/j. engappai.2016.01.005

Cotton, H.M., Segni, L.D., Eck, W., Isaac, B., Price, J., Kushnir-Stein, A., Misgav, H., Price, J., Roll, I., \& Yardeni, A. (2010). Corpus Inscriptionum Iudaeae / Palaestinae: A multi-lingual corpus of the inscriptions from Alexander to Muhammad (1 $1^{\text {st }}$ ed., Vol. 1.1). Berlin/New York: De Gruyter.

Elliott, T., Bodard, G., Milonas, E., Stoyanova, S., Tupman, C., \& Vanderbilt, S. (2007-2013). EpiDoc Guidelines: Ancient documents in TEI XML. Retrieved from [http://www.stoa.org/ epidoc/gl/latest/], 2017/12/09.

Evangelisti, S., Liuzzo, P.M., \& Verreth, H. (2014). Content Harmonisation guidelines, including GIS and terminologies. [Deliverable of the project EAGLE, 1st release]. Retrieved from 
[https://www.eagle-network.eu/wp-content/uploads/2013/06/EAGLE_D2.2.1_Contentharmonisation-guidelines-including-GIS-and-terminologies.pdf], 2017/12/09.

Felicetti, A. \& Murano, F. (2016). Scripta manent: a CIDOC CRM semiotic reading of ancient texts. International Journal on Digital Libraries, 18(4), 263-270. doi: 10.1007/s00799-016-0189-z

Feraudi-Gruénais, F. \& Grieshaber, F. (2016). Digital Epigraphy am Scheideweg? / Digital Epigraphy at a crossroads? [Presented at the Nachnutzung und Nachnutzbarkeit der Forschung im Akademienprogramm Workshop der Nordrhein-Westfälischen Akademie der Wissenschaften und der Künste und der Union der deutschen Akademien der Wissenschaften AG „eHumanities“, Düsseldorf]. doi: 10.11588/heidok.00022141

Liuzzo, P.M. (2015). EAGLE and EUROPEANA. Architecture Problems for Aggregation and Harmonization. In Proceedings of the Symposium on Cultural Heritage Markup (Balisage Series on Markup Technologies 16). Retrieved from [http://www.balisage.net/Proceedings/ vol16/html/Liuzzo01/BalisageVol16-Liuzzo01.html], 2017/12/09.

Liuzzo, P.M. (2017). Mapping Databases to EpiDoc. In S. Orlandi, R. Santucci, F. Mambrini, \& P.M. Liuzzo, (Eds.), Digital and Traditional Epigraphy in Context. Proceedings of the EAGLE 2016 International Conference (pp. 187-200). Roma: Sapienza Università Editrice. doi: 10.13133/978-88-9377-021-7

Liuzzo, P.M., Fasolini, D., \& Rocco, A. (2014). Content Harmonisation guidelines, including GIS and terminologies. [Deliverable of the project EAGLE, 2nd release]. Retrieved from [https://www. eagle-network.eu/wp-content/uploads/2013/06/EAGLE_D2.2.2_Content-harmonisationguidelines-including-GIS-and-terminologies-Second-Release.pdf], 2017/12/09.

Liuzzo, P.M., Mambrini, F., \& Franck, P. (2017). Storytelling and Digital Epigraphy-Based Narratives in Linked Open Data. In M. Ioannides, N. Magnenat-Thalmann, \& G. Papagiannakis (Eds.), Mixed Reality and Gamification for Cultural Heritage (pp. 507-523). Springer: Cham. doi: 10.1007/978-3-319-49607-8_20

Manghi, P., Mannocci, A., Sicilia, M.A., Gomez Pantoja, J., Rubiro Fuentes, J., Rivero Ruiz, E., \& Zoppi, F. (2015). EAGLE metadata model specification. [Deliverable of the project EAGLE, 2nd release]. Retrieved from [https://www.eagle-network.eu/wp-content/uploads/2013/06/ EAGLE_D3.1_EAGLE-metadata-model-specification_v1.1.pdf], 2017/12/09.

Mannocci, A. (2017, January 12). Data Flow Quality Monitoring in Data Infrastructures (PhD thesis). Pisa : Università di Pisa. Retrieved from [https://etd.adm.unipi.it/theses/available/ etd-12232016-151401/unrestricted/PhD_Thesis.pdf], 2017/12/09.

Orlandi, S., Santucci, R., Casarosa, V., \& Liuzzo, P.M. (Eds.). (2014). Information Technologies for Epigraphy and Cultural Heritage: Proceedings of the First EAGLE International Conference (Serie antichistica. Collana Convegni 26). Roma: Sapienza Università Editrice. Retrieved from [http://archiv.ub.uni-heidelberg.de/propylaeumdok/2337/], 2017/12/09.

Orlandi, S., Santucci, R., Mambrini, F., \& Liuzzo, P.M. (Eds.). (2017). Digital and Traditional Epigraphy in Context. Proceedings of the EAGLE 2016 International Conference. Roma: Sapienza Università Editrice. doi: 10.13133/978-88-9377-021-7

Prag, J. (2017). I.Sicily: an epidoc corpus for ancient Sicily. In S. Orlandi, R. Santucci, F. Mambrini, \& P.M. Liuzzo, (Eds.), Digital and Traditional Epigraphy in Context. Proceedings of the EAGLE 2016 International Conference (pp. 83-96). Roma: Sapienza Università Editrice. doi: 10.13133/978-88-9377-021-7

Proceedings of Balisage: The Markup Conference 2017. (2017). (Balisage Series on Markup Technologies 19). Mulberry Technologies, Inc. Retrieved from [https://www.balisage.net/ Proceedings/vol19/masthead.html], 2017/12/09.

Ruiz, E.R., Vassallo, V., \& Liuzzo, P.M. (2014). Networking EAGLE with CIDOC and TEI. [Presented at Conference: CIDOC 2014: Access and Understanding - Networking in the Digital Era]. Retrieved from [http://www.cidoc2014.de/images/sampledata/cidoc/papers/J-2_Vassallo_ Ruiz_Liuzzo_paper.pdf], 2017/12/09. 
Turska, M., Cummings, J., \& Rahtz, S. (2016). Challenging the Myth of Presentation in Digital Editions. Journal of the Text Encoding Initiative, 9. doi: 10.4000/jtei.1453

Verreth, H. (2017). Trismegistos Places, a geographical index for all Latin inscriptions. In S. Orlandi, R. Santucci, F. Mambrini, \& P.M. Liuzzo, (Eds.), Digital and Traditional Epigraphy in Context. Proceedings of the EAGLE 2016 International Conference (pp. 201-208). Roma: Sapienza Università Editrice. doi: 10.13133/978-88-9377-021-7

Wicentowski, J.C. \& Meier, W. (2015). Publishing TEI documents with TEI Simple. In Proceedings of Balisage: The Markup Conference 2015 (Balisage Series on Markup Technologies 15). doi: 10.4242/BalisageVol15.Wicentowski01 